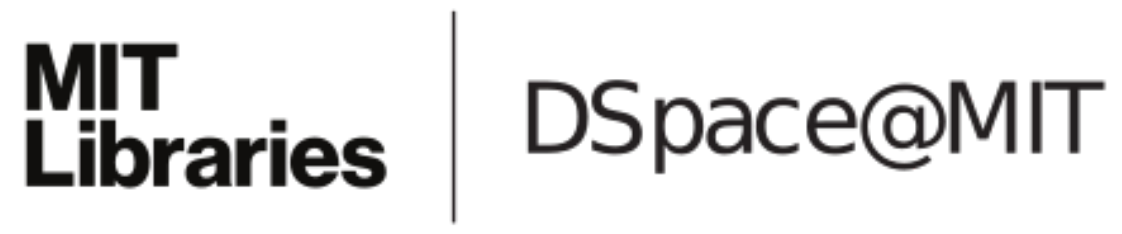

\author{
MIT Open Access Articles
}

Filters and Components With Inductance Cancellation

The MIT Faculty has made this article openly available. Please share how this access benefits you. Your story matters.

Citation: Neugebauer, T.C., J.W. Phinney, and D.J. Perreault. "Filters and Components With Inductance Cancellation." IEEE Trans. on Ind. Applicat. 40, no. 2 (March 2004): 483-491. (c) 2004 IEEE

As Published: http://dx.doi.org/10.1109/TIA.2004.824487

Publisher: Institute of Electrical and Electronics Engineers (IEEE)

Persistent URL: http://hdl.handle.net/1721.1/86933

Version: Final published version: final published article, as it appeared in a journal, conference proceedings, or other formally published context

Terms of Use: Article is made available in accordance with the publisher's policy and may be subject to US copyright law. Please refer to the publisher's site for terms of use. 


\title{
Filters and Components With Inductance Cancellation
}

\author{
Timothy C. Neugebauer, Student Member, IEEE, Joshua W. Phinney, Student Member, IEEE, and
} David J. Perreault, Member, IEEE

\begin{abstract}
Electrical filters are important for attenuating electrical ripple, eliminating electromagnetic interference (EMI) and susceptibility, improving power quality, and minimizing electromagnetic signature. Capacitors are critical elements in such filters, and filter performance is strongly influenced by the capacitor parasitics. This paper introduces a new design technique that overcomes the capacitor parasitic inductance that limits filter performance at high frequencies. Coupled magnetic windings are employed to effectively cancel the parasitic inductance of capacitors, and to add inductance in filter branches where it is desired. The underlying basis of the new technique is treated in detail, and its application to the design of both discrete filters and integrated $L C$ filter components is described. Numerous experimental results demonstrating the high performance of the approach in both discrete filters and integrated filter elements are provided.
\end{abstract}

Index Terms-Capacitor, electromagnetic interference (EMI) filter, equivalent series inductance (ESL), inductance cancellation, integrated filter, integrated passive component.

\section{INTRODUCTION}

$\mathbf{E}$ LECTRICAL filters are designed to prevent unwanted frequency components from propagating from the filter input port to the filter output port, while passing desirable components. In power applications, filters are important for attenuating electrical ripple, eliminating electromagnetic interference (EMI) and susceptibility, improving power quality, and minimizing electromagnetic signature. Such filters typically employ capacitors as shunt elements, and may include inductors as series elements, as illustrated in Fig. 1. The attenuation of a filter stage is determined by the amount of impedance mismatch between the series and shunt paths. For a low-pass filter, minimizing shunt-path impedance and maximizing series-path impedance at high frequencies is an important design goal. Design methods for such filters are described in [1] and [2], for example.

One critical aspect of such filters is the filter capacitor parasitics. Fig. 2 shows a first-order model for a filter capacitor [3], including the equivalent series resistance (ESR), $R_{\mathrm{ESR}}$, and equivalent series inductance (ESL), $L_{\mathrm{ESL}}$, of the capacitor. Fig. 3 illustrates the impedance characteristic of

Paper IPCSD 03-126, presented at the 2002 Industry Applications Society Annual Meeting, Pittsburgh, PA, October 13-18, and approved for publication in the IEEE TRANSACTIONS ON INDUSTRY APPLICATIONS by the Power Electronics Devices and Components Committee of the IEEE Industry Applications Society. Manuscript submitted for review January 1, 2003 and released for publication December 8, 2003. This work was supported by the United States Office of Naval Research under ONR Grant N00014-00-1-0381 and ONR Grant N00014-02-1-0481.

The authors are with the Laboratory for Electromagnetic and Electronic Systems, Massachusetts Institute of Technology, Cambridge, MA 02139 USA (e-mail: neugebat@alum.mit.edu).

Digital Object Identifier 10.1109/TIA.2004.824487

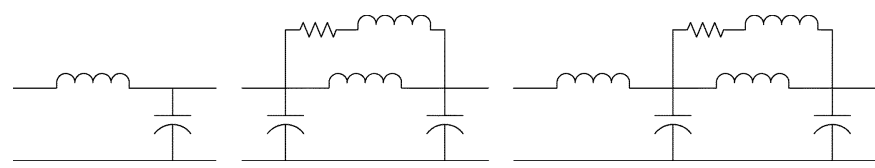

Fig. 1. Some common low-pass filter structures for power applications.

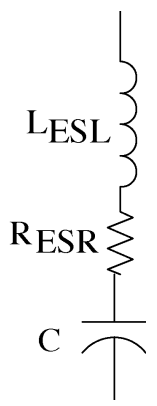

Fig. 2. A model for a real capacitor including ESL and ESR.

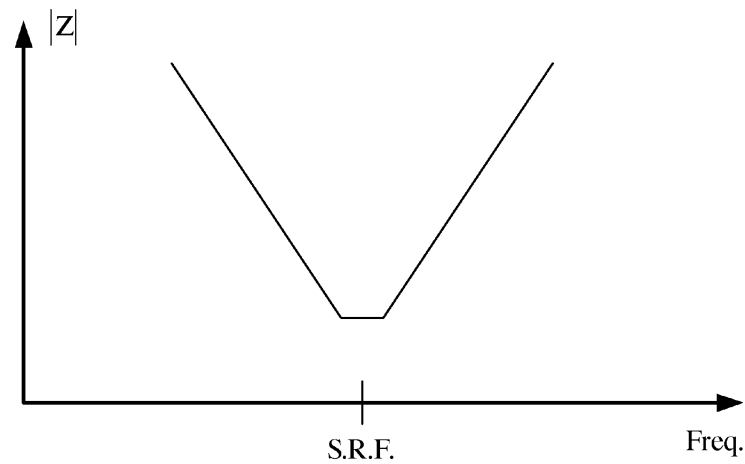

Fig. 3. Illustration of capacitor impedance magnitude versus frequency. High-frequency impedance is dominated by the capacitor ESL.

a typical capacitor across frequency. At high frequencies, the capacitor shunt impedance is dominated by the ESL. For example, a typical aluminum electrolytic capacitor may appear inductive (impedance rising with frequency) at frequencies above $50-100 \mathrm{kHz}$, limiting its ability to shunt ripple at high frequencies. Similarly, large-valued film capacitors typically become inductive in the range of $100 \mathrm{kHz}-1 \mathrm{MHz}$. The traditional approach for overcoming filter capacitor limitations is to parallel capacitors of different types (to cover different frequency ranges) and/or to increase the order of the filter used (e.g., by adding series filter elements such as inductors). Both of these approaches can add considerable size and cost to the filter.

This paper introduces a new design technique that overcomes the capacitor parasitic inductance that limits filter performance at high frequencies. This new technique is based on the application of coupled magnetic windings to effectively cancel the 


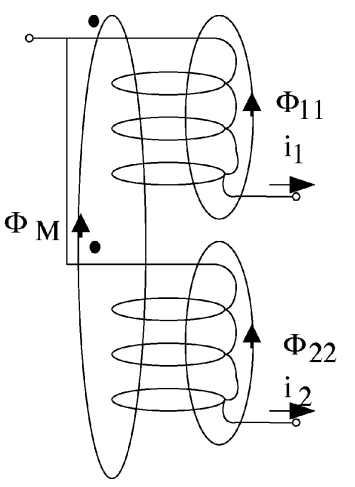

Fig. 4. An end-tapped connection of coupled magnetic windings.

parasitic inductance of capacitors, while introducing inductance in filter branches where it is desired. After treating the underlying basis of the new technique, we address its application to the design of both discrete filters (that is, filters built with discrete components) and novel integrated $L C$ filter components. We also provide experimental results demonstrating the viability and high performance of the approach for both discrete filters and integrated filter elements.

The paper is organized as follows. Section II introduces the use of coupled magnetic windings to overcome capacitor parasitic inductance. Practical implementation of this technique in both discrete filters and integrated filter components is explored in Section III. Section IV presents experimental results demonstrating the new technique, and Section V concludes the paper.

\section{INDUCTANCE CANCELLATION}

Here, we propose how magnetically coupled windings can be used to cancel the effects of capacitor parasitics. Fig. 4 illustrates one possible connection of coupled magnetic windings, which we hereafter refer to as an "end-tapped" connection. In this case, each winding links flux with itself and mutually with the other winding. An electromagnetic analysis of this system leads to an inductance matrix description

$\left[\begin{array}{c}\lambda_{1} \\ \lambda_{2}\end{array}\right]=\left[\begin{array}{cc}\frac{N_{1}^{2}}{\Re_{11}}+\frac{N_{1}^{2}}{\Re_{M}} & \frac{N_{1} N_{2}}{\Re_{M}} \\ \frac{N_{1} N_{2}}{\Re_{M}} & \frac{N_{2}^{2}}{\Re_{22}}+\frac{N_{2}^{2}}{\Re_{M}}\end{array}\right]\left[\begin{array}{l}i_{1} \\ i_{2}\end{array}\right]=\left[\begin{array}{cc}L_{11} & L_{M} \\ L_{M} & L_{22}\end{array}\right]\left[\begin{array}{c}i_{1} \\ i_{2}\end{array}\right]$

where the flux linkages $\lambda_{1}$ and $\lambda_{2}$ are the time integrals of the individual coil voltages, and $i_{1}$ and $i_{2}$ are the individual coil currents. The self-inductances $L_{11}$ and $L_{22}$ and mutual inductance $L_{M}$ are functions of the numbers of coil turns and the reluctances $\Re_{11}, \Re_{22}$, and $\Re_{M}$ of the self and mutual magnetic flux paths. In cases where no magnetic material is present, the behavior of the coupled windings is determined principally by the geometry of the windings. Conservation of energy considerations require that the mutual coupling between the windings be less than or equal to the geometric mean of the self-inductances. That is,

$$
L_{M} \leq \sqrt{L_{11} L_{22}}
$$

Thus, the inductance matrix of (1) is necessarily positive semidefinite. Note that while the constraint (2) limits $L_{M}$ to be

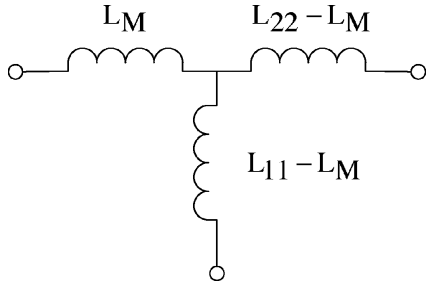

Fig. 5. An equivalent circuit model for end-tapped coupled magnetic windings.

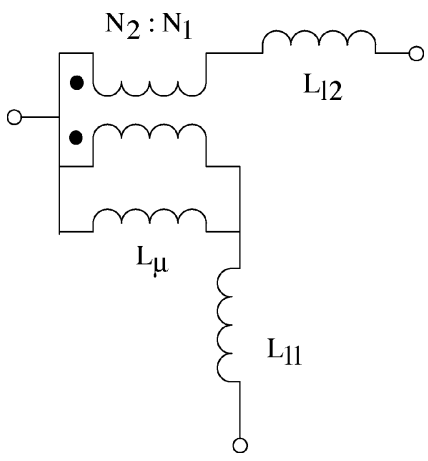

Fig. 6. A physically based circuit model of the coupled magnetic windings.

less than or equal to the geometric mean of $L_{11}$ and $L_{22}$, it may still be larger than one of the two inductances. For example, with proper winding of the coils one may have

$$
L_{11}<L_{M}<\sqrt{L_{11} L_{22}}<L_{22} .
$$

Fig. 5 shows one possible equivalent circuit model for the coupled inductor windings based on the inductance matrix of (1). This model is referred to as the "T" model of the coupled windings. With the ordering of self and mutual inductances of (3), the inductance of one leg of the T model - the vertical leg in Fig. 5-is clearly negative! It is this "negative inductance" that will be utilized to overcome the high-frequency limitations of filter capacitors.

The negative inductance effect arises from electromagnetic induction between the coupled windings. This is readily seen in the physically based circuit model of the coupled windings shown in Fig. 6. (With appropriate parameter values, the circuit models of Figs. 5 and 6 have identical terminal characteristics, and each captures the behavior of the system (1).) We stress that the negative inductance in the $\mathrm{T}$ model does not violate any physical laws. Only one leg of the $T$ model has a negative inductance. The total inductance seen across any winding is - as expected - the positive-valued self-inductance of the winding.

Fig. 7 shows the application of the coupled magnetic windings to a capacitor whose equivalent series inductance (ESL) is to be cancelled. The coupled windings are modeled with the T network of Fig. 5, while the capacitor is shown as an ideal capacitor $C$ in series with parasitic resistance $R_{\mathrm{ESR}}$ and parasitic inductance $L_{\mathrm{ESL}}$. (We also lump any interconnect parasitics into these elements.) When $L_{11}-L_{M}$ is chosen to be negative and close in magnitude to $L_{\mathrm{ESL}}$, a net shunt path inductance $\Delta L=L_{11}-L_{M}+L_{\mathrm{ESL}} \approx 0$ results. The combined network is very advantageous as a filter. A near-zero shunt path impedance (limited only by ESR) is maintained out to much 


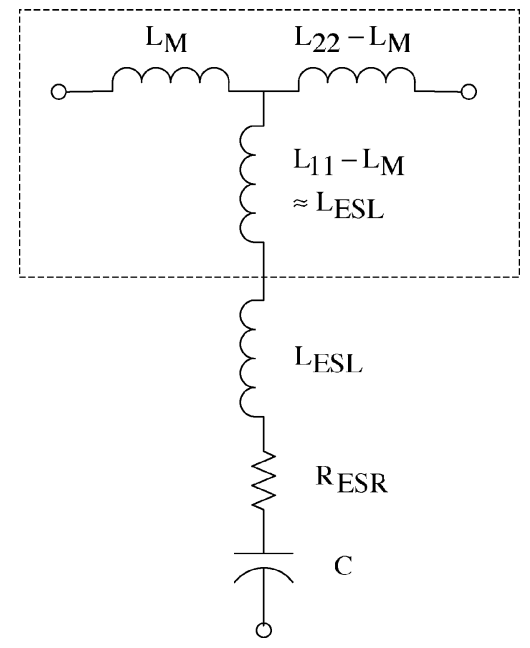

Fig. 7. Application of coupled magnetic windings to cancel the series inductance of a capacitor. Capacitor ESR and ESL are shown explicitly, along with the equivalent $\mathrm{T}$ model of the magnetic windings.

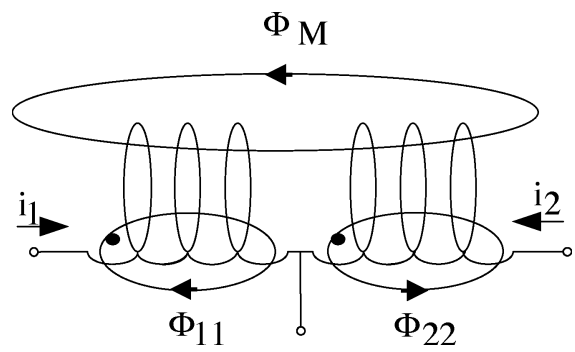

Fig. 8. A center-tapped coupled magnetic winding configuration.

higher frequencies than is possible with the capacitor alone. Furthermore, as $L_{22}$ is much greater than $L_{M}$, the series-path inductance $L_{22}-L_{M}$ serves to increase the order of the filter network, further improving filter performance.

It should be appreciated that other magnetic winding structures can also be used to realize inductance cancellation. Another three-terminal coupled magnetic structure that can be used is shown in Fig. 8. This implementation is advantageous in that it can be formed from a single winding tapped at an appropriate point. An electromagnetic analysis of the system of Fig. 8 results in an inductance matrix

$$
\begin{aligned}
{\left[\begin{array}{l}
\lambda_{1} \\
\lambda_{2}
\end{array}\right] } & =\left[\begin{array}{cc}
\frac{N_{1}^{2}}{\Re_{11}}+\frac{N_{1}^{2}}{\Re_{M}} & \frac{-N_{1} N_{2}}{\Re_{M}} \\
\frac{-N_{1} N_{2}}{\Re_{M}} & \frac{N_{2}^{2}}{\Re_{22}}+\frac{N_{2}^{2}}{\Re_{M}}
\end{array}\right]\left[\begin{array}{l}
i_{1} \\
i_{2}
\end{array}\right] \\
& =\left[\begin{array}{cc}
L_{11} & -L_{M} \\
-L_{M} & L_{22}
\end{array}\right]\left[\begin{array}{l}
i_{1} \\
i_{2}
\end{array}\right]
\end{aligned}
$$

where the self-inductances $L_{11}$ and $L_{22}$ and mutual inductance $L_{M}$ are again functions of the numbers of coil turns $N_{1}, N_{2}$ and the reluctances of the respective magnetic flux paths. The magnitude of the mutual inductance is again limited by the constraint (2), though without the ordering imposed in (3).

The terminal characteristics of the system of Fig. 8 can be modeled with the "T model" of Fig. 9. Again, one branch of the $\mathrm{T}$ model has a negative inductance (in this case equal in magnitude to the mutual inductance $L_{M}$ ). When $L_{M}$ is chosen

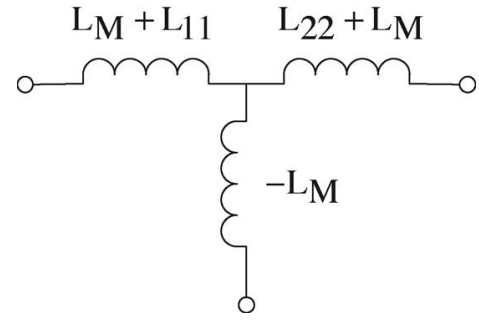

Fig. 9. An equivalent circuit model for the center-tapped coupled magnetic windings.

to be close in magnitude to the equivalent series inductance $L_{\mathrm{ESL}}$ of an electrical circuit path (e.g., through a capacitor) connected to the bottom terminal, a reduced net effective inductance $\Delta L=-L_{M}+L_{\mathrm{ESL}} \approx 0$ results in the capacitor's shunt path.

As described above, coupled magnetic windings are used to cancel inductance in the capacitor branch path (e.g., due to capacitor and interconnect parasitics) and provide filter inductance in a second branch path. In a low-pass filter, this corresponds to a cancellation of the filter shunt-path inductance, and an addition of series path inductance. (The final branch path necessarily has an inductance greater than or equal to the magnitude of the "negative" inductance that is introduced in the capacitor path.) We point out that the use of coupled magnetics in filters is not in itself new. In fact, use of coupled magnetic windings in filters dates at least as far back as the 1920s [4], and has continued up to the present time in many forms [5]-[10] (see [5] for a good review of such usage). The approach described here differs from these existing methods in that the coupling of the windings is utilized to cancel the effects of parasitic inductance in the capacitor and interconnects, permitting dramatic improvements in filtering performance to be achieved.

\section{IMPLEMENTATION}

In this section we consider application of this inductance cancellation technique in the design of both discrete filters and integrated filter components. One important design consideration is that of repeatability: if tuning of individual units is to be avoided, the inductances of both the capacitor and the magnetic windings must be highly repeatable. ${ }^{1}$ Fortunately, unlike capacitance or ESR values, capacitor ESL is typically repeatable to within a few percent. For example, the histograms of Fig. 10(a) and (b) show the distribution of ESL and ESR for a type of electrolytic capacitor that is widely used in filters. The ESR varies over a wide range from 14.2 to $60.9 \mathrm{~m} \Omega$ (outlier not shown). The ESL, by contrast, varies only from 17.29 to $18.13 \mathrm{nH}$ (with a standard deviation of $44.6 \mathrm{pH}$ ), representing a maximum variation in ESL of only $\pm 2.4 \%$ across units. This makes sense: the absence of magnetic materials means that the inductance of the structure depends primarily on geometry, while capacitance and resistance depend on material and interface properties. One may conclude that inasmuch as appropriate coupled magnetic structures can be created, the parasitic inductance can be repeatably cancelled to within a few percent of its original value.

\footnotetext{
${ }^{1}$ Systems incorporating active self-tuning [11]-[13] (e.g., via controllable magnetics [14]-[17]) are also possible. We defer consideration of this approach to a future report.
} 
a)

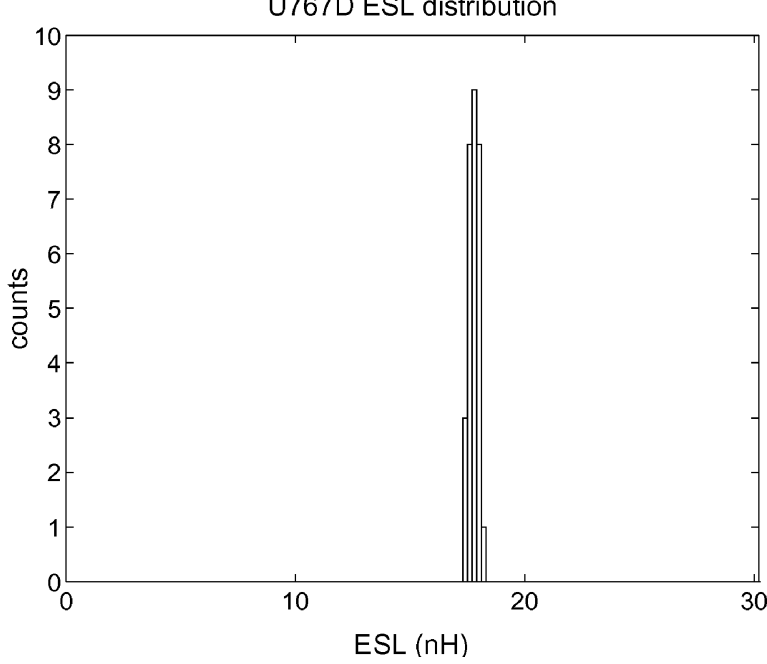

b)

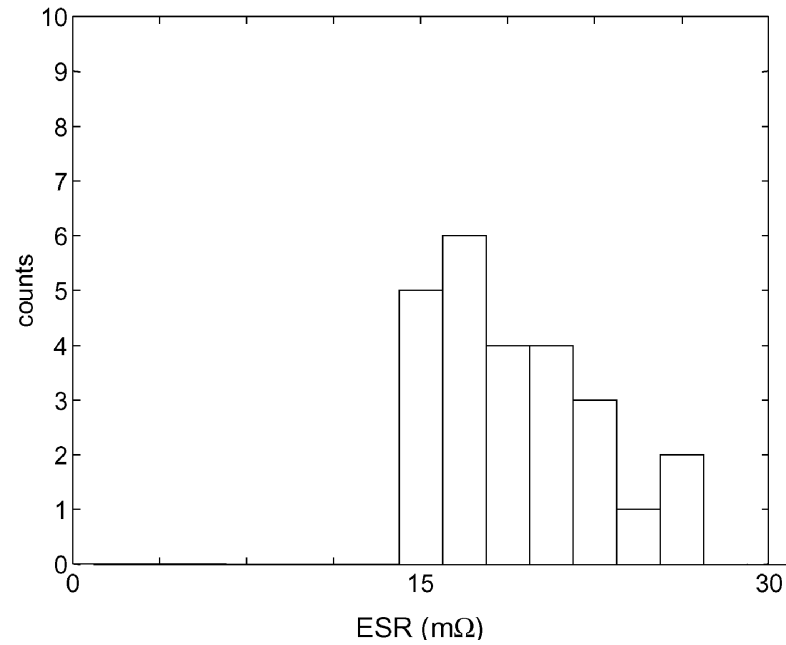

Fig. 10. (a) ESL and (b) ESR histograms for 30 United Chemi-Con U767D $2200-\mu \mathrm{F} 35-\mathrm{V}$ capacitors. ESL range: $17.29-18.13 \mathrm{nH}, \sigma=44.6 \mathrm{pH}$. ESR range: $14.2-60.9 \mathrm{~m} \Omega$ (outlier not shown).

The capacitor inductance to be cancelled in a practical design is typically quite small (e.g., on the order of tens of nanohenrys). Coupled magnetic windings appropriate to the cancellation technique must thus be able to accurately generate a negative effective shunt inductance in this range under all operating conditions. One approach for achieving this is to use coupled windings without magnetic materials. Such "air-core" magnetics are appropriate given the small inductances needed and the desire for repeatability and insensitivity to operating conditions.

Two approaches for employing the proposed inductance cancellation technique are considered in this paper. We first address the use of inductance cancellation methods in the design of filter circuits built with discrete components (e.g., capacitors and inductors) using conventional manufacturing techniques. We then explore the integration of cancellation windings with a capacitor to form an integrated filter element - a three-terminal device providing both a shunt capacitance (with extremely low shunt inductance) and a series inductance.

\section{A. Discrete Filters}

An immediate application of the proposed technology is in the design of discrete filters - that is, filters built with available

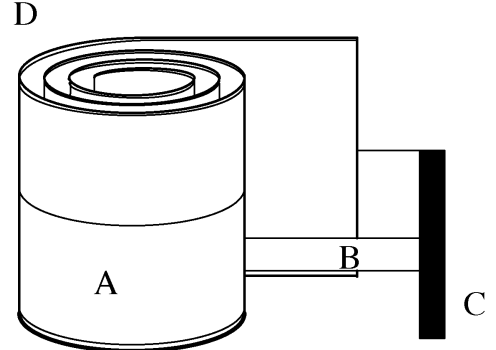

Fig. 11. Integrated filter element $\mathrm{D}$ is constructed by adding magnetically coupled windings A and B over or as part of the basic capacitor structure. The integrated filter element is then a three-terminal device, with the connection of the two magnetic windings brought out as terminal $\mathrm{C}$.

or easily manufactured components using conventional fabrication techniques. In this approach, a coupled winding circuit is connected to a discrete capacitor to provide a very-low-inductance path through the capacitor along with a second high-inductance path. The coupled winding circuit should have repeatable inductance parameters (that are properly matched to the capacitor), and should have minimal size and cost impact on the filter.

One simple implementation method is to print the coupled windings as part of the filter printed circuit board (PCB). Printing the magnetic windings on the PCB results in extremely repeatable magnetic structures and interconnects. Furthermore, it represents essentially no extra cost or volume in the design if the PCB space underneath the filter capacitor can be used for the windings.

We have found air-core PCB windings to be highly effective for the proposed inductance cancellation technique. As will be demonstrated in Section IV, practical printed PCB windings can be implemented using either end-tapped (Fig. 4) or center-tapped (Fig. 8) winding configurations, and can be placed either partially or entirely underneath the capacitor on the PCB. A two-layer circuit board is typically sufficient to implement the windings with the required interconnects accessed at the outside of the spiral windings. The coupled winding circuits demonstrated in this paper were designed using a widely available inductance calculation tool [18] and refined experimentally.

\section{B. Integrated Filter Elements}

In addition to their application in discrete filters, inductance cancellation techniques have application to new filter components. Here, we introduce the integration of coupled magnetic windings (providing inductance-cancellation) with a capacitor to form an integrated filter element - a single three-terminal device providing both a shunt capacitance (with extremely low inductance) and a series inductance. To do this, one can wind inductance-cancellation magnetics on, within, or as part of the capacitor itself. This approach, illustrated in Fig. 11, minimizes the volume of the whole structure, as the same volume is used for the capacitive and magnetic energy storage. For example, starting with a wound (tubular) capacitor, one could wind the coupled magnetics directly on top of the capacitor winding. The magnetic windings can also be implemented through extension or patterning of the capacitor foil or metallization itself. An integrated filter element utilizing inductance cancellation may be 
expected to have far better filtering performance than a capacitor of similar size.

We note that components incorporating both capacitive and inductive coupling have a long history in power applications [19]-[25] and continue to be an important topic of research (e.g., [26]-[29]). However, the aims and resulting characteristics of such prior art integrated elements are quite different than those described here. The approach described here is different in that magnetically coupled windings are utilized to nullify the effects of the parasitic inductance in the capacitive path. This permits dramatic improvements in filtering performance to be achieved as compared to conventional components with relatively modest changes in manufacturing methods.

Other changes in manufacturing methods can also reduce the parasitic inductance of a capacitor. In particular, reductions in the packaging size and the current path can improve the capacitor's performance. However, these methods can only reduce the current loop to a limited extent, and therefore the parasitic inductance will always have a finite size. Safety regulations and practical manufacturing techniques ultimately limit the minimum size of the current loop, and hence the inductance. The proposed technique can ideally cancel out all of the parasitic series inductance regardless of the size and layout of the capacitor. The proposed technique thus has advantages beyond what can be achieved only by minimizing winding and packaging inductance of a conventional capacitor.

As with discrete filters, both end-tapped and center-tapped coupled-winding configurations are possible. (Note that in some integrated implementations, flux associated with current flow in the capacitive element may link the cancellation windings. This changes the details of the magnetic analysis - and may be used to some advantage - but the underlying principles remain the same.) Consider an integrated component having a wound structure, as suggested by Fig. 11. In an end-tapped configuration, the magnetic windings comprise two conductors co-wound and electrically connected at one end (one terminal of the three terminal device.) The other end of one conductor is a second terminal of the device. The other end of the second conductor is connected to one plate of the capacitor. (The magnetic winding may be formed as a direct continuation of the capacitor winding in this case.) The other plate of the capacitor is connected to the third terminal.

In a center-tapped magnetic winding configuration, the coupled magnetic windings may be formed as a single conductor wound concentrically with the capacitor windings. The magnetic winding is tapped (connected to one plate of the capacitor) at a specified point in the winding. The other plate of the capacitor and the two ends of the magnetic winding form the three terminals of the device. Fig. 12 illustrates one possible method for forming the cancellation winding over the capacitor structure and interconnecting it to one capacitor plate.

\section{EXPERIMENTAL RESULTS}

In this section we demonstrate the viability and high performance of the proposed inductance cancellation technology. We validate the approach for both discrete filters and integrated filter elements across a variety of capacitor sizes and types, and

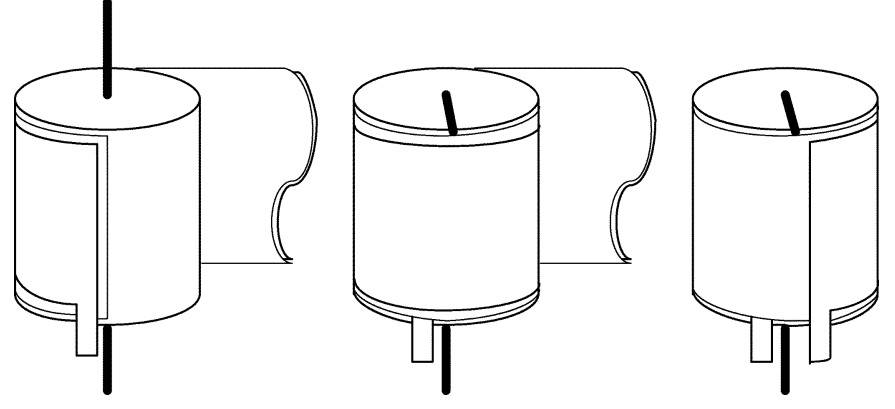

Fig. 12. One construction method for an integrated filter element with a center-tapped winding.

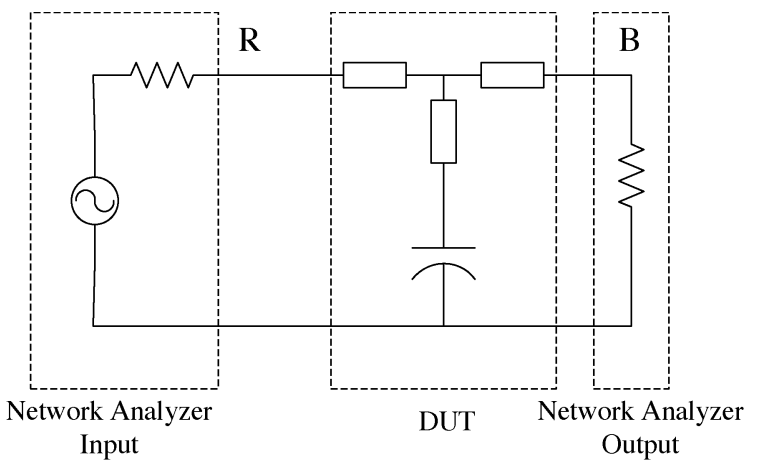

Fig. 13. An experimental setup for evaluating filters and components incorporating an Agilent 4395A network analyzer.

with both end-tapped and center-tapped winding configurations. We also demonstrate the large performance advantage of a prototype integrated filter element in a power converter application.

\section{A. Evaluation Method}

To evaluate the effectiveness of the inductance cancellation method, the test setup of Fig. 13 is used. The device under test (DUT) is either a capacitor, a capacitor plus PCB cancellation windings, or an integrated filter element. The device under test (DUT) is driven from the $50-\Omega$ output of the network analyzer. As the driving point impedance of the DUT is always far less than the output impedance of the network analyzer, the drive essentially appears as a current source. The voltage response is measured at the $50 \Omega$ input of the network analyzer. The input impedance of the network analyzer is much greater than the impedance associated with the series output inductance of the DUT for the frequencies under consideration. Accordingly, this test effectively measures the shunt impedance of the DUT relative to the 50- $\Omega$ input impedance of the network analyzer. Thus, this test focuses on filtering improvements associated with the shunt-path inductance cancellation, while suppressing improvements available through the introduction of series path inductance. In practical application of a filter, one could take advantage of the series inductance provided by the cancellation windings to further improve attenuation performance.

\section{B. End-Tapped Discrete Filter}

Fig. 14 shows a discrete-filter implementation of the inductance cancellation technique for a large film capacitor (Cornell-Dubilier 935C4W10K, $10 \mu \mathrm{F}, 400 \mathrm{~V}$ ). The coupled magnetic windings are printed in the PCB with a rectangular and 


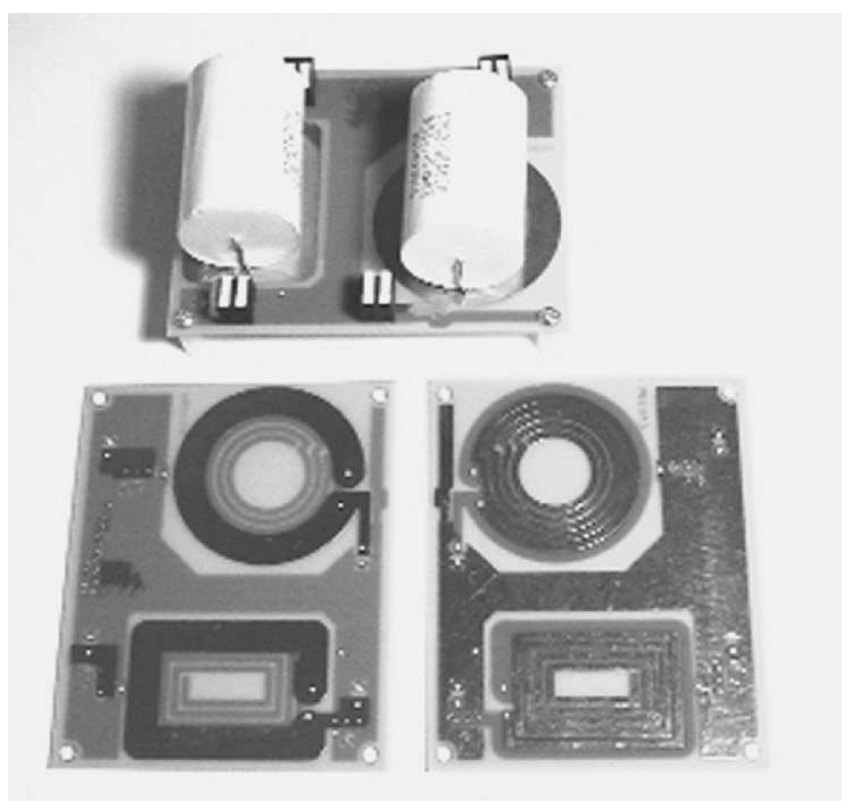

Fig. 14. Discrete filters using Cornell Dubilier 935C4W10K capacitors with end-tapped cancellation windings printed in the PCB. The board at the top has both capacitors mounted. The board in the lower left shows the top (component) side of the board, while the board in the lower right shows the bottom side of the board.

circular coil version on each board. The printed windings are placed in an end-tapped configuration, with the winding connected to the capacitor made from a single turn on the top side of the 0.031 -in-thick board. The second winding is placed on the bottom side of the board and is tapped at a point to maximize inductance cancellation in the system (approximately 2.5 turns are used, placing the output at the other end of the capacitor.) Current return for both the capacitor and filter output current is on a bottom-side ground plane adjacent to the capacitor. Note that the printed windings fit in the board space underneath the capacitor.

Fig. 15 shows comparative experimental results using the test arrangement of Fig. 13 for both a capacitor alone and a capacitor plus cancellation windings. The results are presented for frequencies up to $2 \mathrm{MHz}$, at $10 \mathrm{~dB}$ per division. The capacitor alone is self-resonant at a frequency of about $150 \mathrm{kHz}$, and acts as an inductor at higher frequencies. With cancellation windings, the effective shunt impedance of the filter drops to the value of the ESR and remains there to frequencies higher than $1 \mathrm{MHz}$. At approximately $1.25 \mathrm{MHz}$ the capacitor itself has a secondary resonance, above which its effective ESL and ESR change by several percent. (The secondary resonance is not easily observed in the presented magnitude plot for the capacitor alone because it is overwhelmed by the primary ESL impedance. We have observed such secondary resonances in several large-valued film capacitors.) Despite second-order effects, the experimental results demonstrate that the inductance cancellation technique provides a large reduction in effective shunt-path inductance, resulting in a factor of 10 improvement $(20 \mathrm{~dB})$ in filtering performance out to very high frequencies. This dramatic improvement is achieved at no change in size or cost, since the cancellation windings fit in the board space beneath the capacitor.

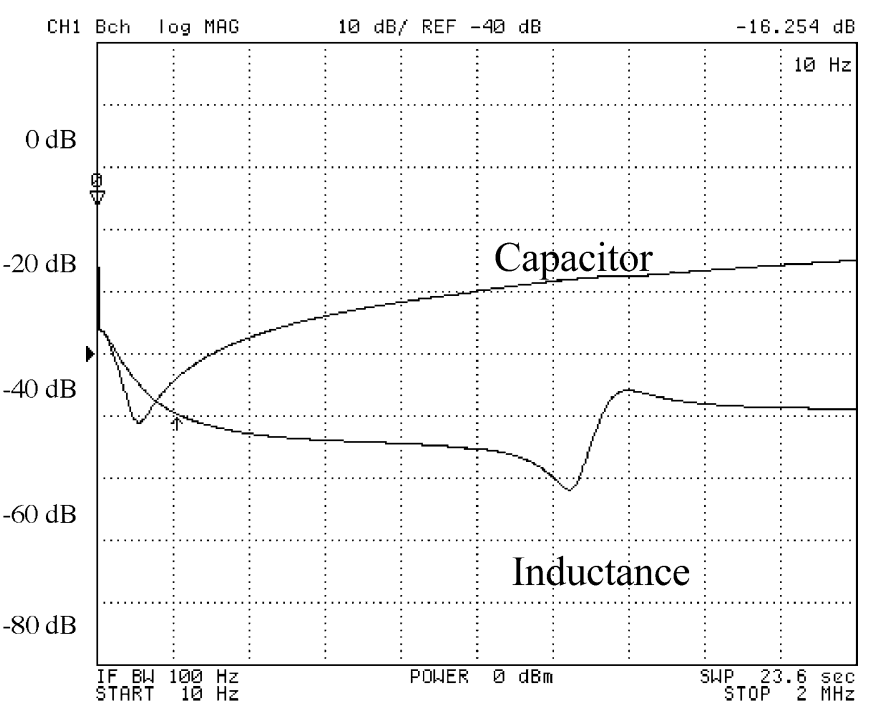

Fig. 15. Performance comparison between a 935C4W10K film capacitor and the inductance cancellation filter of Fig. 14.

\section{Center-Tapped Discrete Filter}

A discrete filter implementation based on an X-type (safety) capacitor (Beyschlag Centrallab 222233824 224, $0.22 \mu \mathrm{F}, 275$ Vac) was also evaluated. Such capacitors are widely used in EMI filters for line applications. Inductance cancellation windings were again formed in the printed circuit board, this time using a center-tapped winding configuration. While not critical to the application, a pair of center-tapped coupled windings was used (one each for the positive and negative terminals of the capacitor) in order to maintain symmetry for common-mode signals. (We have also built a similar circuit utilizing a single coupled winding, with similar results.) In the case considered here, the coupled windings for each terminal comprised a single turn on the top layer of the board and a single turn on the bottom layer of the board.

Fig. 16 shows comparative experimental results using the test setup of Fig. 13 for the $\mathrm{X}$ capacitor with and without the printed cancellation windings. The conducted EMI frequency range up to $30 \mathrm{MHz}$ is considered, with results plotted at $10 \mathrm{~dB}$ per division. The capacitor alone has an ESR of approximately 45 $\mathrm{m} \Omega$ and an ESL of approximately $10 \mathrm{nH}$, resulting in a selfresonant frequency in the vicinity of $3 \mathrm{MHz}$. Addition of the cancellation windings results in dramatic improvement in filtering performance at frequencies above $5 \mathrm{MHz}$ (as much as $26 \mathrm{~dB}$ ). Careful impedance measurements suggest an equivalent $\mathrm{T}$ model with input and output branch inductances of approximately $17.5 \mathrm{nH}$ each and a total shunt-branch inductance of approximately $1.2 \mathrm{nH}$, corresponding to an $88 \%$ reduction in effective capacitor-path inductance. The results confirm the dramatic filtering improvements possible with this technique.

\section{Integrated Filter Element (Film)}

We have also constructed prototype integrated filter elements by winding cancellation windings on the bodies of existing capacitors. Fig. 17 shows a prototype integrated filter element built with a center-tapped winding configuration using the construction method of Fig. 12. (The board also has a capacitor without 


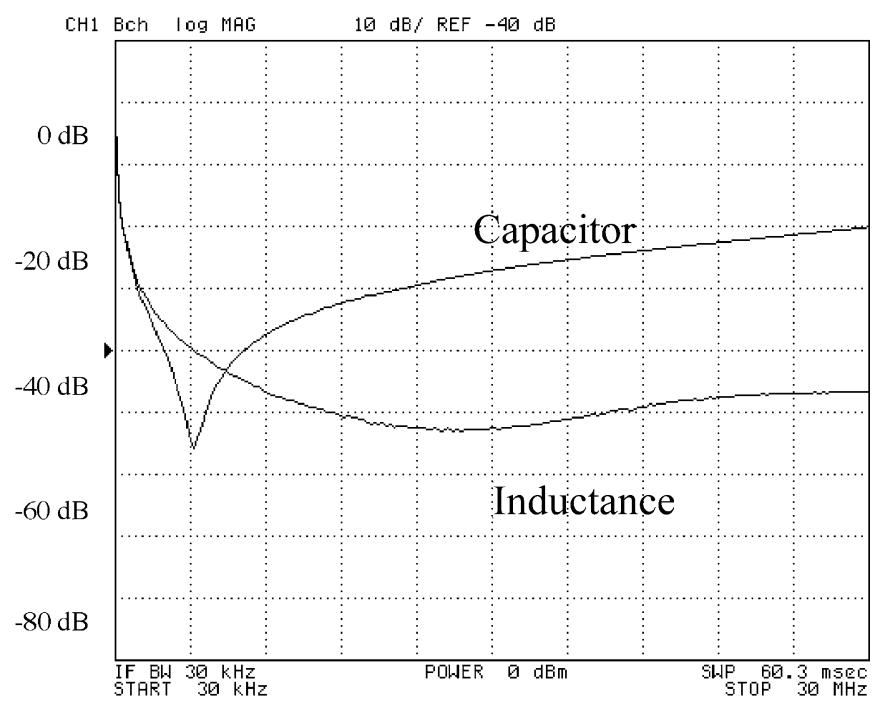

Fig. 16. Comparison of a BC $222233824224 \mathrm{X}$-capacitor to a corresponding discrete filter with center-tapped cancellation windings.

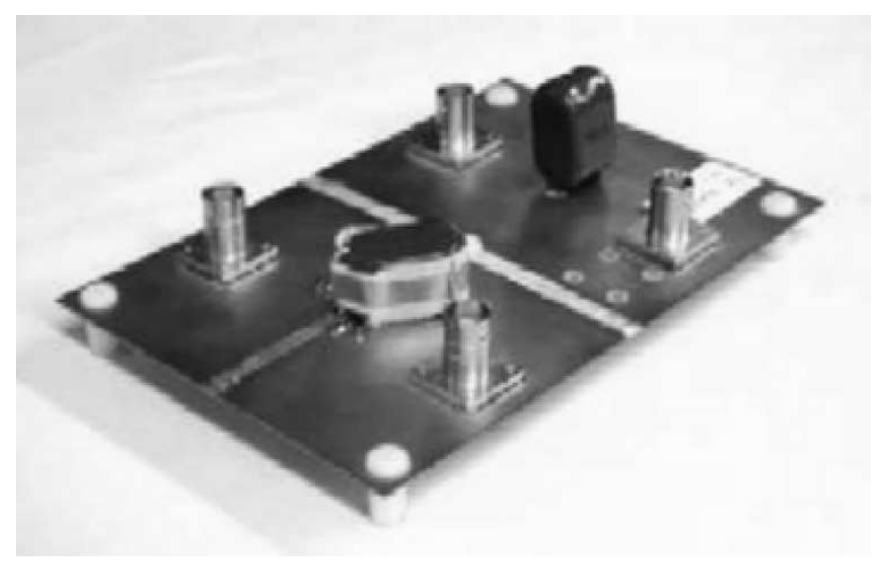

Fig. 17. A prototype integrated filter element based on a Rubycon MMW 106K2A film capacitor and center-tapped cancellation winding. The test board, including a capacitor-only setup, is also shown.

cancellation windings.) The prototype filter element was constructed using a Rubycon MMW 106K2A film capacitor (10 $\mu \mathrm{F}, 100 \mathrm{~V})$. The tapped cancellation winding was wound on the center of the capacitor body with 0.25 -in-wide 1-mil-thick copper tape, using 1-mil-thick mylar tape for insulation. A $330^{\circ}$ winding was placed on the capacitor body and tapped, followed by a continued $225^{\circ}$ winding. The prototype filter element was mounted on a two-sided PCB with the top side split between the filter input and output nodes, and a full-width ground plane on the bottom side of the board. (In the capacitor only case, the input and output nodes are the same.)

Test results using the experimental setup of Fig. 13 are shown in Fig. 18. The capacitor alone exhibits its primary self-resonance at approximately $600 \mathrm{kHz}$, with a second resonance in the vicinity of $3 \mathrm{MHz}$. (Again, this is characteristic of some kinds of high-valued film capacitors.) The integrated filter element nullifies the principle ESL characteristic, making the effects of the secondary resonances more pronounced. Nevertheless, a tremendous improvement in filtration performance is obtained at high frequencies, exceeding $30 \mathrm{~dB}$ (a factor of 30 ) for frequencies above $7 \mathrm{MHz}$.

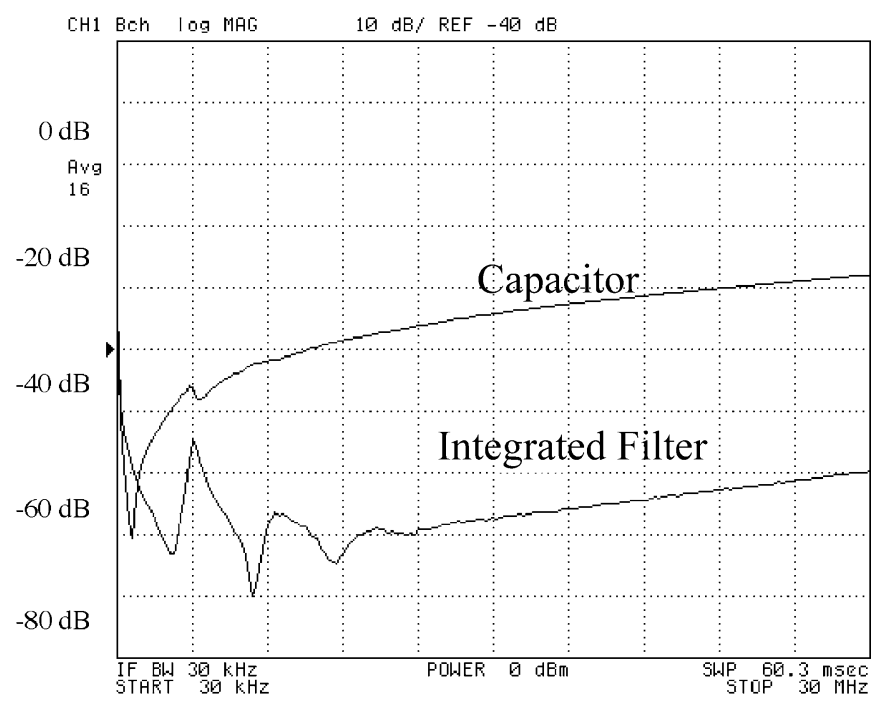

Fig. 18. Comparison of a Rubycon MMW 106K2A film capacitor to the prototype integrated filter element of Fig. 17.

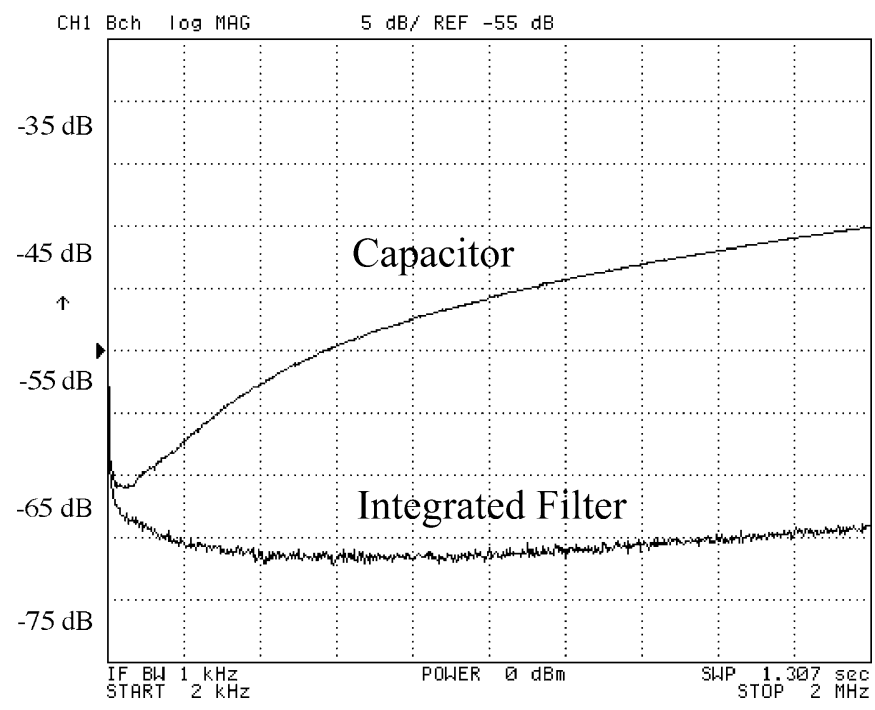

Fig. 19. Comparison of a United Chemi-con U767D, 2200- $\mu$ F electrolytic capacitor to the a corresponding prototype integrated filter element.

\section{E. Integrated Filter Element (Electrolytic)}

An integrated filter element based on a $2200-\mu \mathrm{F}$ electrolytic capacitor (United Chemi-Con U767D, $2200 \mu \mathrm{F}, 35 \mathrm{~V}$ ) was also evaluated. Such capacitors are widely used in filters for automotive applications. The center-tapped cancellation winding was wound 0.25 in from the top of the capacitor body with 0.5-in-wide 1-mil-thick copper tape, using 1-mil-thick mylar tape for insulation. A 3.25-turn winding was placed on the capacitor body and tapped, followed by a continued 3.125-turn winding. The test board setup was similar to that described above.

Test results using the experimental setup of Fig. 13 are shown in Fig. 19. The impedance of the capacitor alone begins to rise in the vicinity of $100 \mathrm{kHz}$ due to ESL effects. By contrast, the integrated filter element continues to attenuate the input out to much higher frequencies, resulting in more than a 10-dB improvement at $200 \mathrm{kHz}$, and increasing to more than $20 \mathrm{~dB}$ above $1 \mathrm{MHz}$. 


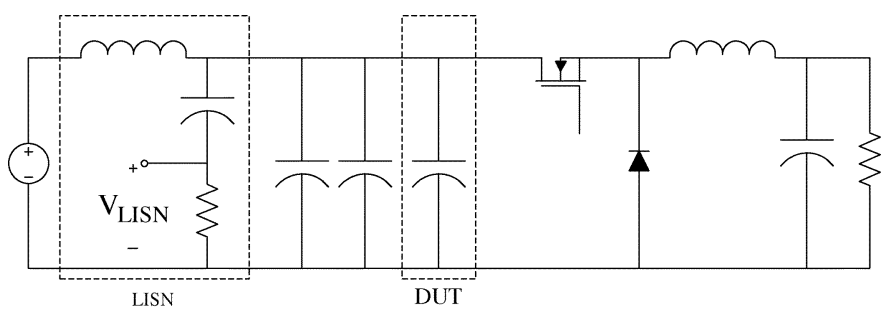

Fig. 20. Test setup used to measure the conducted EMI performance of the integrated filter element.

It appears that the use of inductance cancellation has achieved a reduction in shunt-path ESR as compared to the capacitor in Fig. 19. However, as illustrated in Fig. 10, ESR values for this type of capacitor vary over a wide range (15-60 $\mathrm{m} \Omega$ ). The apparent improvement is primarily due to the difference in ESR between the two capacitors In the test devices. It should be noted that implementing inductance cancellation will generally introduce a small amount of circuit resistance, some of which appears in the shunt path. (The shunt path component is typically higher in end-tapped design.) In the cases examined, however, the added resistances have been in the $\mathrm{m} \Omega$ range, and have not been a significant factor from either a loss or a filtration perspective.

\section{F. Application to a Power Converter}

To evaluate the proposed approach under realistic operating conditions, a further integrated filter element was developed and employed as the main element in the input filter of a buck converter. This prototype filter element was again based on a United Chemi-Con U767D series 2200- $\mu$ F 35-V capacitor, but in this case an end-tapped winding configuration was used. The shunt-path winding was implemented as 1.75 turns (on the capacitor body) of 1-in-wide 1-mil-thick copper foil insulated with 1-mil-thick mylar tape. The series-path winding was formed using several turns of 18 -gauge magnet wire coiled tightly over the shunt-path winding and glued in place. An end-point of the series path winding yielding good inductance cancellation was found empirically. The resulting prototype filter element reduced the effective shunt-path inductance by approximately a factor of five as compared to a capacitor alone, while providing additional series filter-path inductance.

The conducted EMI performance of the integrated filter element was measured using the test setup of Fig. 20. The prototype element was employed as the main input filter element for a buck converter. As is typical in input filter applications, a pair of small ceramic capacitors ( $22 \mu \mathrm{F}$, United Chemi-Con TCD 51E1E226M) was placed in parallel with the DUT. Ripple attenuation performance was measured using standard EMI test measurements in an A-B comparison between the prototype filter element and a capacitor. The $\mathrm{dc} / \mathrm{dc}$ converter was operated at a switching frequency of $100 \mathrm{kHz}$ with approximately $50 \%$ duty ratio and a 10-A dc output current. The Line Impedance Stabilization Network (LISN) voltage was measured with a spectrum analyzer via a $20-\mathrm{dB}$ attenuator.

The relative performance of the prototype filter element and a capacitor alone is illustrated in Fig. 21. As can be seen, the attenuation of the prototype filter element exceeds that
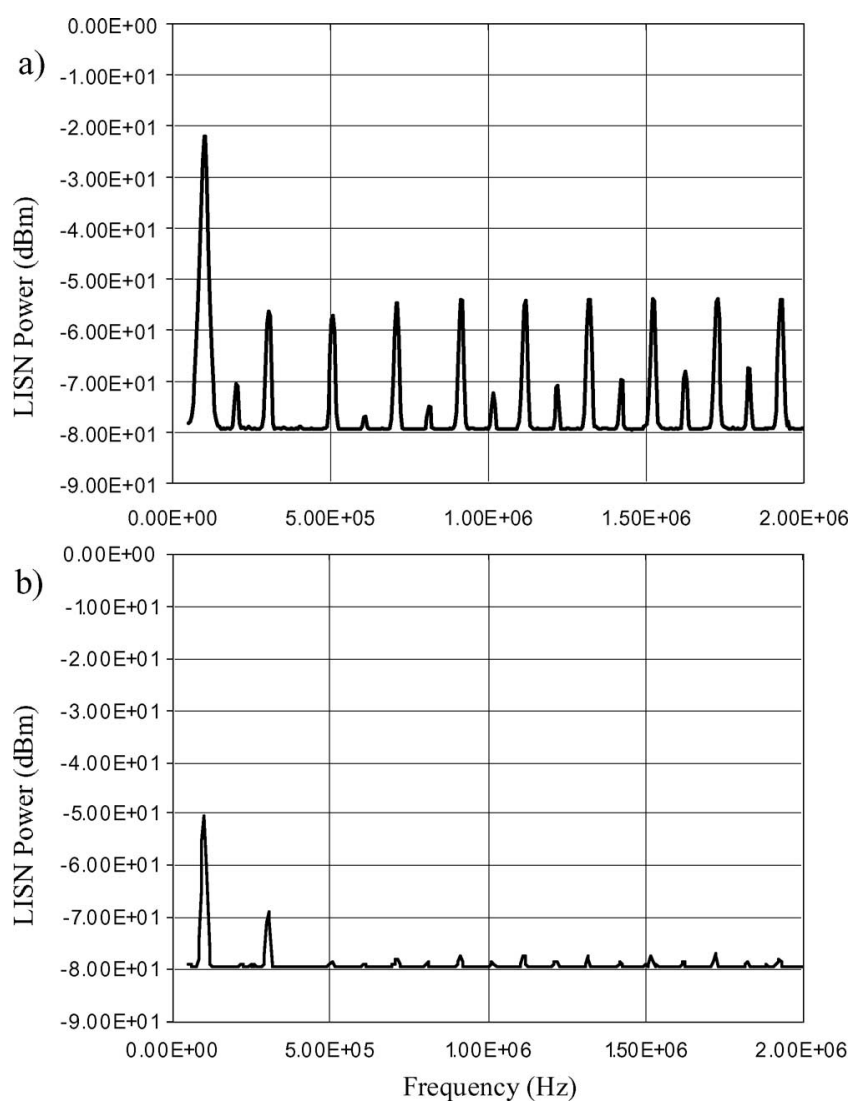

Fig. 21. LISN power spectra for the case of (a) the capacitor alone and (b) the integrated filter element. The converter was operated at $50 \%$ duty cycle at $10-\mathrm{A}$ dc output current.

of the capacitor alone by over $25 \mathrm{~dB}$ (a factor of 17) across the measured spectrum $(100 \mathrm{kHz}-2 \mathrm{MHz})$. This represents a large improvement in filtration capability without a significant increase in component volume. Furthermore, substantial additional improvements may be expected in such applications as design techniques for integrated filter elements are refined.

The use of an inductance cancellation transformer will benefit some applications and not others. A general rule to determine if this technique will be useful for a given application is to examine all three branches in the $\mathrm{T}$ model. A candidate application should significantly benefit from a reduction in inductance in one branch, but not be overly sensitive to comparable inductance increases in the other branches. In this test setup, the DUT was placed next to the switching device and therefore adding some inductance (tens of nanohenrys) in series with the MOSFET. This added inductance, which is on the order of the switching device's lead inductance, only slightly affects the switching characteristics of the converter. In this case, no noticeable rise in switching loss was expected or detected. If needed, a second capacitor can be placed between the integrated filter element and the switching device.

\section{CONCLUSION}

Electrical filters are important for attenuating electrical ripple, eliminating EMI and susceptibility, improving power quality, and minimizing electromagnetic signature. Capacitors are critical elements in such filters, and filter performance is 
strongly influenced by the capacitor parasitics. This paper has introduced a new design technique that overcomes the capacitor parasitic inductance that limits filter performance at high frequencies. This new technique is based on the application of coupled magnetic windings to effectively cancel capacitor parasitic inductance, while introducing inductance in filter branches where it is desired. After treating the underlying basis of the technique, the paper addressed its application to the design of both discrete filters and novel integrated $L C$ filter components. Numerous experimental results were provided that demonstrate the high performance of the approach in both discrete filters and integrated filter components across a wide variety of capacitor sizes and types.

\section{REFERENCES}

[1] T. K. Phelps and W. S. Tate, "Optimizing passive input filter design," in Proc. 6th Nat. Solid-State Power Conversion Conf., May 1979, pp. G1-1-G1-10.

[2] M. J. Nave, Power Line Filter Design for Switched-Mode Power Supplies. New York: Van Nostrand Reinhold, 1991.

[3] P. T. Krein, Elements of Power Electronics. New York: Oxford Univ. Press, 1998, pp. 381-392.

[4] G. B. Crouse, "Electrical filter," U.S. Patent 1920 948, Aug. 1, 1933.

[5] D. C. Hamill and P. T. Krein, "A 'zero' ripple technique applicable to any DC converter," in Proc. IEEE PESC, June 1999, pp. 1165-1171.

[6] S. Feng, W. A. Sander, and T. G. Wilson, "Small-capacitance nondissipative ripple filters for DC supplies," IEEE Trans. Mag., vol. 6, pp. 137-142, Mar. 1970.

[7] R. P. Severns and G. E. Bloom, Modern DC-to-DC Switchmode Power Converter Circuits. New York: Van Nostrand Reinhold, 1985.

[8] J. W. Kolar, H. Sree, N. Mohan, and F. C. Zach, "Novel aspects of an application of 'zero'-ripple techniques to basic converter topologies," in Proc. IEEE PESC, June 1997, pp. 796-803.

[9] G. E. Bloom and R. Severns, "The generalized use of integrated magnetics and zero-ripple techniques in switchmode power converters," in Proc. IEEE PESC, 1984, pp. 15-33.

[10] S. Senini and P. J. Wolfs, "The coupled inductor filter: analysis and design for AC systems," IEEE Trans. Ind. Electron., vol. 45, pp. 574-578, Aug. 1998.

[11] J. W. Phinney, "Filters with active tuning for power applications," S.M. Thesis, Dept. Elect. Eng. Comput. Sci., Massachusetts Inst. Technol., Cambridge, MA, May 2001.

[12] J. W. Phinney and D. J. Perreault, "Filters with active tuning for power applications," IEEE Trans. Power Electron., vol. 18, pp. 636-647, Mar. 2003.

[13] D. L. Logue and P. T. Krein, "Optimization of power electronic systems using ripple correlation control: a dynamic programming approach," in Proc. IEEE PESC, June 2001, pp. 459-464.

[14] R. Heartz and H. Buelteman, "The application of perpendicularly superposed magnetic fields," AIEE Trans., pt. I, vol. 74, pp. 655-660, Nov. 1955.

[15] N. Saleh, "Variable microelectronic inductors," IEEE Trans. Comp. Hybrids, Manufact. Technol., vol. CHMT-1, pp. 118-124, Mar. 1978.

[16] H. J. McCreary, "The magnetic cross valve," AIEE Trans., pt. II, vol. 70, pp. $1868-1875,1951$

[17] F. J. Beck and J. M. Kelly, "Magnetization in perpendicularly superposed direct and alternating fields," J. Appl. Phys., vol. 19, pp. 551-562, June 1948.

[18] A. Kamon, L. M. Silveira, C. Smithhisler, and J. White, FastHenry USER'S GUIDE. Cambridge, MA: MIT Press, 1996.

[19] R. Reeves, "Choke-capacitor hybrid as a flourescent lamp ballast," Proc. Inst. Elect. Eng., vol. 122, no. 10, pp. 1151-1152, Oct. 1975.

[20] —_, "Inductor-capacitor hybrid," Proc. Inst. Elect. Eng., vol. 122, no. 11, pp. 1323-1326, Nov. 1975

[21] P. N. Murgatroyd and N. J. Walker, "Lumped-circuit model for inductorcapacitor hybrid," Electron. Lett., vol. 12, no. 1, pp. 2-3, Jan. 1976.

[22] R. J. Kemp, P. N. Murgatroyd, and N. J. Walker, "Self resonance in foil inductors," Electron. Lett., vol. 11, no. 15, pp. 337-338, July 1975.
[23] M. Ehsani, O. H. Stielau, J. D. van Wyk, and I. J. Pitel, "Integrated reactive components in power electronic circuits," IEEE Trans. Power Electron., vol. 8, pp. 208-215, Apr. 1993.

[24] M. Ehsani, P. Le Polles, M. S. Arefeen, I. J. Pitel, and J. D. Van Wyk, "Computer-aided design and application of integrated LC filters," IEEE Trans. Power Electron., vol. 11, pp. 182-190, Jan. 1996.

[25] I. W. Hofsajer, J. A. Ferreira, and J. D. van Wyk, "Design and analysis of planar integrated L-C-T components for converters," IEEE Trans. Power Electron., vol. 15, pp. 1221-1227, Nov. 2000.

[26] F. Wilmot, E. Labouré, F. Costa, S. Faucher, C. Joubert, and F. Forest, "Design, optimization and electromagnetic modeling of integrated passive components for power electronic," in Proc. IEEE PESC, June 2001, pp. 1932-1937.

[27] L. Zhao, J. T. Strydom, and J. D. Van Wyk, “An integrated resonant module for a high-power soft-switching converter," in Proc. IEEE PESC, June 2001, pp. 1944-1948.

[28] K. Laouamri, J. C. Crebier, J.-P. Ferrieux, and T. Chevalier, "Construction and modeling of integrated LCT structure for PFC resonant converter," in Proc. IEEE PESC, June 2001, pp. 1949-1954.

[29] J. C. Crebier, T. Chevalier, K. Laouamri, and J. P. Ferrieux, "Study and analysis of wounded integrated L-C passive components," in Proc. IEEE PESC, June 2001, pp. 2137-2142.

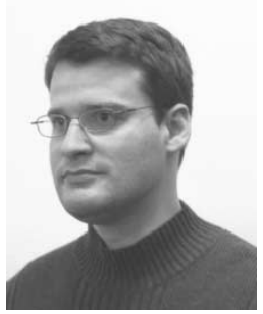

Timothy C. Neugebauer $\left(\mathrm{S}^{\prime} 00\right)$ received the B.S degree in electrical engineering in 1997 from Union College, Schenectady, NY, and the M.S. degree in 1999 from Massachusetts Institute of Technology, Cambridge, where he is currently working toward the $\mathrm{Ph} . \mathrm{D}$. degree in power electronics and has worked in the areas of $\mathrm{dc} / \mathrm{dc}$ converters, multi-level inverters, and the design of passive elements in the Laboratory for Electromagnetic and Electronic Systems.

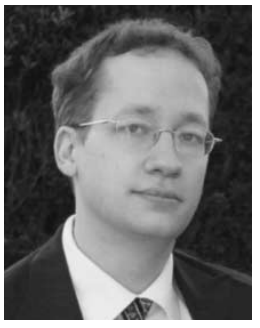

Joshua W. Phinney (S '97) received the B.S. degree from the University of Illinois, Chicago, in 1999, and the S.M. degree from Massachusetts Institute of Technology, Cambridge, in 2001, both in electrical engineering.

He is currently a Research Assistant in the Laboratory for Electromagnetic and Electronic Systems, Massachusetts Institute of Technology, where his research interests include the design and control of miniaturized power converters, power MEMS, and hybrid passive components.

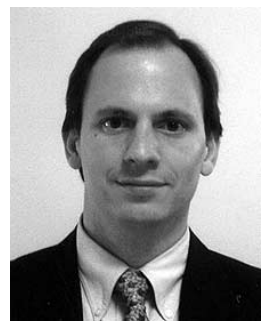

David J. Perreault (S'91-M'97) received the B.S. degree from Boston University, Boston, MA, in 1989, and the S.M. and Ph.D. degrees from Massachusetts Institute of Technology (MIT), Cambridge, MA, in 1991 and 1997, respectively.

In 1997, he joined the MIT Laboratory for Electromagnetic and Electronic Systems as a Postdoctoral Associate, and became a Research Scientist in the laboratory in 1999. In July 2001, he joined the MIT Department of Electrical Engineering and Computer Science as an Assistant Professor. At present, his research interests are in design, manufacturing, and control techniques for power electronic systems and components, and in their use in industrial, commercial, transportation, and medical applications. He teaches a graduate-level course in power electronics at MIT, and is a Consultant to industry in the field.

Dr. Perreault is a Member of Tau Beta Pi and Sigma $\mathrm{Xi}$, and is a recipient of the IEEE Richard M. Bass Outstanding Young Power Electronics Engineer Award and the ONR Young Investigator Award. 